\title{
External ocular surface bacterial isolates and their antimicrobial susceptibility patterns among pre-operative cataract patients at Mulago National Hospital in Kampala, Uganda
}

Barnabas Mshangila ${ }^{1,2}$, Musana Paddy $^{1}$, Henry Kajumbula ${ }^{3}$, Charles Ateenyi-Agaba' ${ }^{1}$ Binta Kahwa ${ }^{1}$ and Jeremiah Seni ${ }^{3,4^{*}}$

\begin{abstract}
Background: Endophthalmitis is a severe complication of cataract surgery which leads to high ocular morbidity and visual loss even with antibiotic treatment. Bacterial ocular floras are the implicated causative agents. This study was undertaken to evaluate the external ocular surface bacterial isolates and their antimicrobial susceptibility patterns among pre-operative cataract patients at Mulago National Hospital.

Methods: This cross sectional study enrolled consecutively 131 patients scheduled for routine cataract surgery in the Department of Ophthalmology at Mulago National Hospital in Kampala, Uganda. Eyelid margin and conjunctival swabs were collected and processed using standard microbiological procedures to identify bacterial isolates and their respective antimicrobial susceptibility patterns.

Results: Of 131 patients involved (mean age $63.3 \pm 14.5$ years), 54.2\% (71/131) were females. The eyelid margin and conjunctival samples were culture positive in $59.5 \%(78 / 138)$ and $45.8 \%(60 / 138)$ respectively. The most common organisms identified were Coagulase-negative Staphylococci (CoNS) [65.9\% (91/138)] and Staphylococcus aureus [21.0\% (29/138)]. CoNS showed the highest resistance to tetracycline $(58.2 \%, 53 / 91)$ and erythromycin $(38.5 \%$, 35/91), whereas in S. aureus the resistance to tetracycline and erythromycin were 55.2\% (16/29) and 31.0\% (9/29) respectively. Methicillin resistant CoNS (MRS) and Methicillin resistance S. aureus (MRSA) were 31.9\% (29/91) and $27.6 \%(8 / 29)$ respectively. There were low resistance rates for CoNS, S. aureus and other bacterial isolates to ciprofloxacin (11.1\%-24.2\%), gentamicin (5.6-31.0\%), tobramycin (17.2\% -25.3\%) and vancomycin (0.0\%).

Conclusion: CONS and S. aureus are the most common bacterial isolates found on the external ocular surface of the pre-operative cataract patients. Ciprofloxacin, gentamicin, tobramycin and vancomycin showed the lowest resistance rates to all bacterial isolates, therefore may be used to reduce bacteria load in the conjunctiva sac among cataract patients prior to surgery.
\end{abstract}

Keywords: Antimicrobial susceptibility, Cataract patients, Uganda

\footnotetext{
* Correspondence: senijj80@gmail.com

${ }^{3}$ Department of Medical Microbiology, Makerere University College of Health Sciences, P.O. Box 7072, Kampala, Uganda

${ }^{4}$ Department of Microbiology and Immunology, Catholic University of Health and Allied Sciences Bugando, P.O. Box 1464, Mwanza, Tanzania

Full list of author information is available at the end of the article
} 


\section{Background}

Endophthalmitis is an inflammatory condition of the eye often caused by bacterial infection [1,2]. It is a rare but dreaded complication of cataract surgery, as it leads to high ocular morbidity and visual loss even with antibiotic treatment [3].

Most bacteria responsible for postoperative ocular infection are part of the normal microbial flora of the conjunctiva and eyelids of the patients [4,5]. Grampositive pathogens are responsible for $60 \%$ to $80 \%$ of acute infections, of which Coagulase-negative Staphylococci (CoNS) are the most frequently isolated pathogens, followed by Staphylococcus aureus and Streptococcus spp [3,5-7]. Gram-negative organisms are responsible for up to $15 \%$ of the infections $[7,8]$. These bacteria are carried into the eye as surface fluid refluxes through the wound during surgery [4,9]. Also, instruments or intraocular lenses may become contaminated if they touch the ocular surface $[9,10]$.

Use of prophylactic antibiotics in cataract surgery reduces the number of organisms in the conjunctiva and eyelids and thus, reduces the risk of postoperative infection [11-13]. Trends of bacterial resistance have been shown to increase among commonly used antibiotics such as penicillins, erythromycin, and tetracycline [14], however the trend is variable to topical fluoroquinolones, a group of broad-spectrum bactericidal agents most frequently used as pre- and postoperative prophylaxis for ocular surgeries. In some areas the resistance trend is increasing [15-17], whereas in other settings only less than $15 \%$ of $S$. aureus, CoNS, Streptococcus spp and Gram negative bacteria were resistance to quinolones $[7,8,14,18]$. Low resistance to vancomycin, cefuroxime and newer quinolones such as ofloxacin, or gatifloxacin has been shown among CoNS, S. aureus and Streptococcus spp $[6,8,13,18,19]$. The underlying causes on the increase in antimicrobial resistance are complex and mostly related to interconnected factors related to inherent pathogens' factors, arbitrary and prolonged use of the drugs and the common practice of self-medication $[1,20]$.

The incidence of postoperative endophthalmitis following cataract surgery in Mulago National Hospital recorded in the year 2010 [2.9\% (12/412)] was higher than the findings from studies in different countries where the rates were less than $0.1 \%[2,13,21-24]$. In spite of this relatively higher rate there is no standard evidence based protocol for the choice of antimicrobial agent to prevent post-operative infections in this setting.

Therefore, this study aimed at assessing the external ocular surface bacterial isolates from pre-operative cataract patients' eyelids and conjunctival samples and their antimicrobial susceptibility patterns at Mulago National Hospital.

\section{Methods}

\section{Study design and sampling process}

This was a hospital based cross-sectional study conducted from September 2011 to March 2012 in the Department of Ophthalmology at Mulago National Hospital. The study involved 131 pre-operative patients who were scheduled for cataract surgery during the study period. Patients with nasolacrimal duct obstruction, prior use of systemic or local antibiotics and/or steroids in the past week, current contact lens wearer and children who required general anesthesia were excluded from the study.

\section{Data collection and laboratory procedures}

The entry point for recruiting patients to participate in this study was during biometry session, whereby, patients who met the inclusion criteria were invited to participate. A thorough explanation on the purpose of the research was provided to all study participants prior to seek for a written informed consent.

External ocular examination using a slit lamp biomicroscope to rule out any focus of infection or inflammation was done thoroughly in all patients and then, demographic data were collected using structured questionnaire.

Ocular swabs were aseptically collected by the principal investigator from patients in the morning on the day of surgery before the application of topical anesthetic, mydriatics, antibiotic or povidone-iodine. Lid margin specimens were collected first followed by conjuntival specimens from the same eye. The patient was asked to look up, and then the lower eyelid margin was swabbed with a sterile cotton swab (Biolab, HUNGARY) moistened with sterile saline, employing a continuous stroke from the nasal to temporal side and then a second stroke from temporal to nasal side. The inferior conjunctival fornix was swabbed by another sterile cotton swab (Biolab, HUNGARY ${ }^{\oplus}$ ), employing the same direction and strokes as for the lid margin without touching eyelid or lashes. The swabs were then inoculated into Brain-heart infusion broth (Biolab ${ }^{\oplus}, \mathrm{HUNGARY}$ ) and processed in the Clinical Microbiology Laboratory of Makerere University College of Health Sciences using standard operating procedures as follows:

\section{Culture and identification}

Samples incubated in Brain-heart infusion broth overnight were sub-cultured into blood agar, chocolate agar and MacConkey (Biolab ${ }^{\oplus}$, HUNGARY) agar and incubated at $35-36^{\circ} \mathrm{C}$ for $24-48$ hours. Identification of bacteria was based on conventional microbiological methods. These included Gram stain, hemolytic activity on sheep blood agar, catalase reaction, coagulase reaction, optochin disk test, bacitracin disk test, hippurate hydrolysis and CAMP tests for Gram positive bacteria. For Gram negative bacteria identification was based on colony morphology on blood 
agar and MacConkey agar and reactions on triple sugar iron, hydrogen sulphide production, indole, motility, citrate, urease and oxidase tests [25].

\section{Drug susceptibility tests}

A standard disc diffusion technique for drug susceptibility test (DST) was performed among all identified isolates as recommended by Clinical and Laboratory Standard Institute (CLSI) [26] on Mueller-Hinton agar (Biolab ${ }^{\circ}$, HUNGARY). The following antibiotics which are currently available on the market and are in routine ophthalmic use were tested: Chloramphenicol $(30 \mu \mathrm{g})$, Gentamycin $(10 \mu \mathrm{g})$, Tobramycin $(10 \mu \mathrm{g})$, Oxacillin $(1 \mu \mathrm{g})$, Polymyxcin-B, Erythromycin $(15 \mu \mathrm{g})$, Vancomycin $(30 \mu \mathrm{g})$, Tetracycline $(30 \mu \mathrm{g})$, Ciprofloxacin $(5 \mu \mathrm{g})$, and Streptomycin $(10 \mu \mathrm{g})$ (Biolab ${ }^{\circ}$, HUNGARY). Multidrug resistance (MDR) bacteria were defined as isolates which are resistance to three or more classes of drugs [27].

Apart from conventional methods, isolates confirmation and drug susceptibility testing were also done using the Phoenix Automated instrument (Becton-Dickson, Sparks Maryland) as per manufacturer's instruction.

\section{Data analysis}

Data collected was entered into the computer software (EpiData 3.1), cleaned and analyzed using SPSS 17.1 software according to the study objectives. Continuous variables were described as mean ( \pm standard deviation). Categorical variables were described as proportion and were analyzed to compare the significance of difference in distribution by using Chi square test or Fischer's exact test where appropriate. The difference in distribution was considered significant if $\mathrm{p}$-value was less than 0.05 .

\section{Quality control}

Aseptic techniques were strictly observed during sample collection, transportation and processing. The standard positive and negative reference control strains used were Staphylococcus aureus ATCC 25923, Staphylococcus aureus ATCC 43300, Staphylococcus epidermidis ATCC 12228 and Escherichia coli ATCC 25922.

\section{Study clearance and ethical considerations}

Permission to conduct this study was obtained from the Institutional Review Board (IRB) of Makerere University College of Health Sciences and Mulago Hospital Research Committee. A written informed consent was obtained from all study participants. Confidentiality was ensured by giving anonymous codes to the study participants. All protocols and procedures in this study complied with the Declaration of Helsinki.

\section{Results}

A total of 131 pre-operative cataract surgery patients were recruited in the study. The mean age was $63.3 \pm 14.5$ years (range 23 to 98 years). Of these, $54.2 \%$ (71/131) were females. Majority $(84.0 \%, 110 / 131)$ of the participants were living in the Central region, followed by Eastern region $(11.5 \%, 15 / 131)$, western region $(3.8 \%, 5 / 131)$ and only $0.76 \%$, (1/131) were from Northern region. The general educational level of the study population was found to be low with only $23.7 \%$ (31/131) having had formal education beyond primary level. More than half of the participants $(57.3 \%, 75 / 131)$ had outdoor occupation.

\section{Eyelid and conjunctival bacterial isolates}

Culture was positive in $59.5 \%$ (78/131) of the eyelid margin samples and in $45.8 \%(60 / 131)$ of the conjunctival samples. The most common bacterial isolates from the eyelid margin were Coagulase-negative staphylococci $66.7 \%$ (52/78) followed by Staphylococcus aureus 20.5\% (16/78), whereas the respective bacteria accounted for 65\% (39/60) and $(21.7 \%(13 / 60)$ from conjunctival specimens. Of all the CoNS isolates, Staphylococcus epidermidis [76.9\% (70/91)] and Staphylococcus saprophyticus [18.7\% (17/91)] were common. Gram negative bacteria accounted for $10.1 \%$ (14/138) from both eyelid and conjuctival swabs (Table 1).

CoNS showed the highest resistance to tetracycline $(58.2 \%, 53 / 91)$, followed by erythromycin $(38.5 \%, 35 / 91)$, whereas in $S$. aureus the resistance to tetracycline and erythromycin were $55.2 \%(16 / 29), 31.0 \%(9 / 29)$ respectively. There were low resistance rates for CoNS, S. aureus and other bacterial isolates to ciprofloxacin (11.1\%-24.2\%), gentamicin (5.6-31.0\%), and tobramycin (17.2\% - 25.3\%). Methicillin resistant CoNS (MRS) and Methicillin resistance S. aureus (MRSA) were 31.9\% (29/91) and 27.6 $(8 / 29)$ respectively. All Gram positive bacterial isolates were sensitive to vancomycin (Table 2).

MDR isolates among CoNS, S. aureus and other isolates were found to be $39.6 \%$ (36/91), 27.6\% (8/29) and $16.7 \%(3 / 18)$ respectively. Bacteria isolates (irrespective

Table 1 Proportion of bacterial isolates from eyelid and conjunctival specimens

\begin{tabular}{lccc}
\hline Organisms & Eyelid & Conjunctiva & Total \\
\hline Staphylococcus epidermidis & $40(57.1 \%)$ & $30(42.9 \%)$ & $70(100.0 \%)$ \\
Staphylococcus aureus & $16(55.2 \%)$ & $13(44.8 \%)$ & $29(100.0 \%)$ \\
Staphylococcus saprophyticus & $8(47.1 \%)$ & $9(52.9 \%)$ & $17(100.0 \%)$ \\
Streptococcus pneumonia & $1(25.0 \%)$ & $3(75.0 \%)$ & $4(100.0 \%)$ \\
Other CoNs $^{*}$ & $4(100.0 \%)$ & $0(0.0 \%)$ & $4(100.0 \%)$ \\
Gram negative rods $^{* *}$ & $9(64.3 \%)$ & $5(35.7 \%)$ & $14(100.0 \%)$ \\
Total $^{\text {Staphylococcus caprae }}$ & $78(56.5 \%)$ & $60(43.5 \%)$ & $138(100.0 \%)$ \\
\hline
\end{tabular}

"Staphylococcus caprae (2), Staphylococcus hominis (1) and Staphylococcus hemolyticus (1).

${ }^{* *}$ Enterobacter cloacae (8), Proteus mirabilis (3) and Acinetobacter spp (3). 
Table 2 Antimicrobial susceptibility pattern of eyelid and conjunctiva isolates

\begin{tabular}{|c|c|c|c|c|c|c|c|c|c|c|c|}
\hline \multirow[t]{2}{*}{ Bacterial isolates } & & \multicolumn{10}{|c|}{ Antimicrobial drugs } \\
\hline & & Oxa $^{1}$ & $\mathrm{Chlr}^{2}$ & $\mathrm{Erth}^{3}$ & Gent $^{4}$ & Tetra $^{5}$ & Cipro $^{6}$ & Vanco $^{7}$ & Strep $^{8}$ & Poly ${ }^{9}$ & Tobra $^{10}$ \\
\hline CoNS, n (\%) & $S$ & $62(68.1)$ & $64(70.3)$ & $56(61.5)$ & $72(79.1)$ & $38(41.8)$ & $69(75.8)$ & $91(100)$ & $61(67.0)$ & $63(69.2)$ & $68(74.7)$ \\
\hline$N=91$ & $\mathrm{R}$ & $29(31.9)$ & $27(29.7)$ & $35(38.5)$ & $19(20.9)$ & $53(58.2)$ & $22(24.2)$ & $0(0.0)$ & $30(33.0)$ & $28(30.8)$ & $23(25.3)$ \\
\hline S. aureus, n (\%) & $S$ & $21(72.4)$ & $21(72.4)$ & $20(69.0)$ & $20(69.0)$ & $13(44.8)$ & $21(72.4)$ & $29(100)$ & $28(96.6)$ & $28(96.6)$ & $24(82.8)$ \\
\hline$N=29$ & $\mathrm{R}$ & $8(27.6)$ & $8(27.6)$ & $9(31.0)$ & $9(31.0)$ & $16(55.2)$ & $8(27.6)$ & $0(0.0)$ & $1(3.4)$ & $1(3.4)$ & $5(17.2)$ \\
\hline Others*, n (\%) & $\mathrm{S}$ & $1(83.3)$ & $10(55.6)$ & $1(25.0)$ & $17(94.4)$ & $15(83.3)$ & $16(88.9)$ & $4(100)$ & $15(83.3)$ & $14(77.8)$ & $14(77.8)$ \\
\hline $\mathrm{N}=18$ & $\mathrm{R}$ & $3(16.7)$ & $8(44.4)$ & $3(75.0)$ & $1(5.6)$ & $3(16.7)$ & $2(11.1)$ & $0(0.0)$ & $3(16.7)$ & $4(22.2)$ & $4(22.2)$ \\
\hline
\end{tabular}

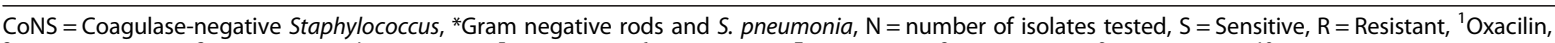
${ }^{2}$ Chloramphenical, ${ }^{3}$ Erythromycin, ${ }^{4}$ Gentamycin, ${ }^{5}$ Tetracycline, ${ }^{6}$ Ciprofloxacin, ${ }^{7}$ Vancomycin, ${ }^{8}$ Streptomycin, ${ }^{9}$ Polymyxcin-B, ${ }^{10}$ Tobramycin. Others ${ }^{*}$ : Erythromycin and Vancomycin were tested in S. pneumonia isolate only.

of species) from eyelid and conjunctiva showed no significant difference in antimicrobial resistance profiles (Table 3).

\section{Discussion}

Of 131 pre-operative patients with cataract recruited in the study, more than three quarter were above 50 years. This finding was similar to other studies $[8,28]$ and is because the prevalence of cataract increases with age. Majority of patients were from the central region, with primary school education and were engaging in outdoor occupation.

Culture positivity of the eyelid margin samples (59.5\%) and conjunctival samples (45.8\%) were less than the rates obtained from other studies $[8,14,29]$ but relatively higher than another similar study [28], this may be attributable to different culture techniques used in these studies. The finding of more bacterial isolates in the eyelid samples compared to conjunctival samples is due to colonization and recurrent introduction of bacteria from adjacent skin to the eyelid margin, whereas the presence of physical, biochemical and immunologic defensive mechanisms on the conjunctiva tend to clear microbes [30]. Similar to other related studies [8,14,28,29,31,32], Gram positive bacteria were commonly isolated with CoNS and S. aureus predominating as opposed to Gram negatives which accounted for less than $10 \%$ on both eyelid and conjunctival samples. Of the CoNS isolated in this study, S. epidermidis accounted for more than two third whereas other CoNS were leastly isolated. These findings are closely related to other studies [28,29]. It is well known that other bacteria such as Propionibacterium spp and Corynebacterium spp may be found on the ocular surfaces [1], but none of these were isolated in the present study. CoNS, S. aureus and other Streptococcus spp (which are usually found as normal flora) have been implicated as potential causes of post-surgical endophthalmitis [3-5,7], thus their identification from preoperative patients in this study calls for introduction an ongoing surveillance to establish the trend essential for infection control in this setting.

This study found high rates of resistance to erythromycin and tetracycline among CoNS and S. aureus, the findings which are similar to other studies $[28,31]$. These can be due to readily availability of these antibiotics, thus liable to indiscriminate use as well as the common practice of self-medication found in Uganda. Resistance to chloramphenicol among CoNS, S. aureus and other isolates were high ranging from $27.6 \%$ to $44.4 \%$ and there were low resistance rates to ciprofloxacin, gentamicin and tobramycin. Furthermore, the invitro-susceptibility results of gentamicin compared to tobramycin are promising in this setting as gentamicin is readily available and less expensive than tobramycin. These findings have also been shown in other similar studies $[8,28]$. The proportion of MRS (31.9\%) and MRSA (27.6\%) among CoNS and S. aureus respectively are relatively similar to another study [29] but higher than the rate reported from another study [8], the difference may be attributable to colonization status

Table 3 Comparison of resistance profiles of eyelid and conjunctival bacterial isolates

\begin{tabular}{lcccc}
\hline Drugs & $\begin{array}{c}\text { Eyelid isolates, } \\
\mathbf{n}(\%) \\
(\mathbf{N}=\mathbf{7 8})\end{array}$ & $\begin{array}{c}\text { Conjunctival } \\
\text { isolates, } \mathbf{n}(\%) \\
(\mathbf{N}=60)\end{array}$ & Chi-2 & p-value \\
\hline Oxacillin & $22(31.9)^{*}$ & $19(34.6)^{* *}$ & 0.0979 & 0.754 \\
Chloramphenicol & $27(34.6)$ & $16(26.7)$ & 0.9989 & 0.318 \\
Erythromycin & $31(66.0)^{*}$ & $16(34.0)^{* *}$ & 3.2611 & 0.071 \\
Gentamicin & $17(21.8)$ & $12(20.0)$ & 0.0658 & 0.798 \\
Tetracycline & $41(52.6)$ & $31(51.7)$ & 0.0109 & 0.917 \\
Ciprofloxacin & $16(20.5)$ & $16(26.7)$ & 0.7210 & 0.396 \\
Vancomycin & $0(0.0)^{*}$ & $0(0.0)^{* *}$ & - & - \\
Streptomycin & $22(28.2)$ & $12(20.0)$ & 1.2297 & 0.267 \\
Polymyxcin & $22(28.2)$ & $11(18.3)$ & 1.8164 & 0.178 \\
Tobramycin & $18(23.1)$ & $14(23.3)$ & 0.0013 & 0.972 \\
\hline
\end{tabular}

${ }^{*} \mathrm{~N}=69$ and ${ }^{* *} \mathrm{~N}=55$ (antimicrobial tests involved Gram positive bacteria only). 
of the study population in the respective settings. The isolation of MRS and MRSA signify that these patients cannot benefit from $\beta$-lactamase inhibitors such as penicillins, cephalosporins, monobactams and carbepenems as preoperative prophylactic agents. All Gram positive bacterial isolates in this study were susceptible to vancomycin. Other similar studies also have showed profoundly low resistance rates among bacteria to vancomycin $[8,14,28,31]$. The MDR isolates among CoNS (39.6\%), S. aureus $(27.6 \%)$ and other isolates $(16.7 \%)$ in the present study and another study in the same setting [33] are relatively higher than from other studies $[8,28,31]$, showing a growing problem of MDR and thus, emphasizing the need for ongoing antimicrobial resistance surveillance to influence infection control and prevention in this setting. Similar to another study [29], there was no difference in antimicrobial resistance profiles among bacteria isolates from eyelid and conjunctiva samples. This raising trend in bacteria resistance at Mulago National Hospital and in other regions $[15,29,34]$ can be limited by judicious prophylactic use of antibiotics, drug susceptibility test guided therapy and ensuring continuous antimicrobial resistance surveillance $[17,34]$.

\section{Conclusion}

The most common bacteria found on the external ocular surface of the pre-operative cataract patients at Mulago National Hospital are CoNS and Staphylococcus aureus, majority of these showed high resistances to tetracycline and erythromycin. All bacterial isolates showed the highest susceptibility rates to ciprofloxacin, gentamicin, tobramycin and vancomycin, and therefore these antibiotics may be used to reduce bacteria load in the conjunctiva sac among cataract patients prior to surgery and thus prevent postoperative endophthalmitis.

\section{Competing interests}

The authors declare that they have no competing interests.

\section{Authors' contributions}

Conceived and designed the study: BM, MP, BK and JS. Specimens' collection: BM. Supervised the study: MP, HK, CA and BK. Analyzed the data: BM and JS. Wrote the manuscript: BM, MP, HK, AT, BK and JS. All authors have read and approved the final manuscript.

\section{Acknowledgements \\ The authors are thankful to patients in the Ophthalmology ward for their willingness to participate in the study; Waiswa Muwazulu, Hannington Baluku and Andrew Akampurira for excellent technical assistance; and all staff in the Department of Ophthalmology and Department Medical Microbiology for their support. This work was funded by Ministry of Health and Social Welfare, Tanzania to BM.}

\section{Author details}

'Department of Ophthalmology, Makerere University College of Health Sciences, P.O. Box 7072, Kampala, Uganda. ${ }^{2}$ Mbeya Referral Hospital, P.O. Box 419, Mbeya, Tanzania. ${ }^{3}$ Department of Medical Microbiology, Makerere University College of Health Sciences, P.O. Box 7072, Kampala, Uganda. ${ }^{4}$ Department of Microbiology and Immunology, Catholic University of Health and Allied Sciences Bugando, P.O. Box 1464, Mwanza, Tanzania.
Received: 5 June 2013 Accepted: 12 November 2013

Published: 15 November 2013

\section{References}

1. Mandell GL, Bennett JE, Dolin R (Eds): Principles and Practice of Infectious Diseases. 6th edition. Philadelphia, Pa, USA: Churchill Livingstone; 2005.

2. Jambulingam M, Parameswaran SK, Lysa S, Selvaraj M, Madhavan HN: A study on the incidence, microbiological analysis and investigations on the source of infection of postoperative infectious endophthalmitis in a tertiary care ophthalmic hospital: an 8-year study. Indian J Ophthalmol 2010, 58(4):297-302.

3. Callegan MC, Engelbert M, Parke DW 2nd, Jett BD, Gilmore MS: Bacterial endophthalmitis: epidemiology, therapeutics, and bacterium-host interactions. Clin Microbiol Rev 2002, 15(1):111-124.

4. Speaker MG, Milch FA, Shah MK, Eisner W, Kreiswirth BN: Role of external bacterial flora in the pathogenesis of acute postoperative endophthalmitis. Ophthalmology 1991, 98(5):639-649. discussion 650.

5. Bannerman TL, Rhoden DL, MCAllister SK, Miller JM, Wilson LA: The source of coagulase-negative staphylococci in the Endophthalmitis Vitrectomy Study, A comparison of eyelid and intraocular isolates using pulsed-field gel electrophoresis. Arch Ophthalmol 1997, 115(3):357-361.

6. Morrissey I, Burnett R, Viljoen L, Robbins M: Surveillance of the susceptibility of ocular bacterial pathogens to the fluoroquinolone gatifloxacin and other antimicrobials in Europe during 2001/2002. J Infect 2004, 49(2):109-114.

7. Benz MS, Scott IU, Flynn HW Jr, Unonius N, Miller D: Endophthalmitis isolates and antibiotic sensitivities: a 6-year review of culture-proven cases. Am J Ophthalmol 2004, 137(1):38-42.

8. Arantes TE, Cavalcanti RF, Diniz Mde F, Severo MS, Lins Neto J, Castro CM: Conjunctival bacterial flora and antibiotic resistance pattern in patients undergoing cataract surgery. Arq Bras Oftalmol 2006, 69(1):33-36.

9. Sherwood DR, Rich WJ, Jacob JS, Hart RJ, Fairchild YL: Bacterial contamination of intraocular and extraocular fluids during extracapsular cataract extraction. Eye (Lond) 1989, 3(Pt 3):308-312.

10. Doyle A, Beigi B, Early A, Blake A, Eustace P, Hone R: Adherence of bacteria to intraocular lenses: a prospective study. Br J Ophthalmol 1995, 79(4):347-349.

11. Colleaux KM, Hamilton WK: Effect of prophylactic antibiotics and incision type on the incidence of endophthalmitis after cataract surgery. Can J Ophthalmol 2000, 35(7):373-378.

12. Montan PG, Wejde G, Koranyi G, Rylander M: Prophylactic intracameral cefuroxime, Efficacy in preventing endophthalmitis after cataract surgery. J Cataract Refract Surg 2002, 28(6):977-981.

13. Wood M, Bowman R, Daya SM: Prophylactic cefuroxime and endophthalmitis in Tanzania, East Africa. J Cataract Refract Surg 2008, 34(1):9-10.

14. Ta CN, Chang RT, Singh K, Egbert PR, Shriver EM, Blumenkranz MS, Mino de Kaspar $\mathrm{H}$ : Antibiotic resistance patterns of ocular bacterial flora: a prospective study of patients undergoing anterior segment surgery. Ophthalmology 2003, 110(10):1946-1951.

15. Alexandrakis G, Alfonso EC, Miller D: Shifting trends in bacterial keratitis in south Florida and emerging resistance to fluoroquinolones. Ophthalmology 2000, 107(8):1497-1502.

16. Graves A, Henry M, O'Brien TP, Hwang DG, Van Buskirk A, Trousdale MD: In vitro susceptibilities of bacterial ocular isolates to fluoroquinolones. Cornea 2001, 20(3):301-305.

17. Kowalski RP, Karenchak LM, Romanowski EG: Infectious disease: changing antibiotic susceptibility. Ophthalmol Clin North Am 2003, 16(1):1-9.

18. Chalita MR, Hofling-Lima AL, Paranhos A Jr, Schor P, Belfort R Jr: Shifting trends in in vitro antibiotic susceptibilities for common ocular isolates during a period of 15 years. Am J Ophthalmol 2004, 137(1):43-51.

19. ESCRS: Prophylaxis of postoperative endophthalmitis following cataract surgery: results of the ESCRS multicenter study and identification of risk factors. J Cataract Refract Surg 2007, 33:978-988.

20. Buchman TG, Dushoff J, Effron MB, Ehrlich PR, Fitzpatrick S, Laxminarayan R: Antibiotic overuse: the influence of social norms, McDonnell Norms Group. J Am Coll Surg 2008, 207(2):265-275.

21. Pot MC: Stilma JS: [Low complication rate with cataract operations carried out by registrars in ophthalmology]. Ned Tijdschr Geneeskd 2008, 152(10):563-568.

22. Oduyebo OO, Odugbemi TO, Idewu A, Adefule-Ositelu A, Aibinu IE, Ogunro A: Incidence of postoperative eye infections in a private eye hospital in Lagos, Nigeria. Nig Q J Hosp Med 2010, 20(3):138-143. 
23. Lin $M$, Zhang $W$, Liu Y, Wang L, Ding Y, Wu X, Shi Y, Sun L, Li Y: Nosocomial acute-onset postoperative endophthalmitis at a university teaching hospital in China. J Hosp Infect 2011, 79(4):323-327.

24. de Luz RA, Padoveze MC, Cvintal T: Epidemiologic surveillance of postoperative endophthalmitis in a specialized ophthalmologic center in Sao Paulo, Brazil. Am J Infect Control 2012, 40(1):e1-e3.

25. Koneman EW, Allen SD, Janda WM, Schreckenberger PC: Color Atlas and Textbook of Diagnostic Microbiology. 5th edition. Philadelphia, PA: Lippincott, Williams \& Wilkins Publishers; 1997.

26. CLSI: Perfomance Standards for Antimicrobial Susceptibility Testing; Twenty First Information Supplement. Vol. CLSI Document M100-S21. Wayne, PA: Clinical and Laboratory Standards Institute; 2011.

27. D'Agata EM: Rapidly rising prevalence of nosocomial multidrug-resistant, Gram-negative bacilli: a 9-year surveillance study. Infect Control Hosp Epidemiol 2004, 25(10):842-846.

28. Aghadoost D, Khorshidi A: Antibiotic Resistance Patterns of Ocular Surface Bacterial Flora. J Infect Dis Antimicrob Agents 2005, 22:53-57.

29. Olson R, Donnenfeld E, Bucci FA Jr, Price FW Jr, Raizman M, Solomon K, Devgan U, Trattler W, Dell S, Wallace RB, et al: Methicillin resistance of Staphylococcus species among health care and nonhealth care workers undergoing cataract surgery. Clin Ophthalmol 2010, 4:1505-1514.

30. Pepose JS, Holland GN, Wilhelmus KR (Eds): Ocular Infection and Immunity. St. Louis: Mosby; 1996.

31. de Kaspar MH, Koss MJ, He L, Blumenkranz MS, Ta CN: Antibiotic susceptibility of preoperative normal conjunctival bacteria. Am J Ophthalmol 2005, 139(4):730-733.

32. Rongrungruang $Y$, Tantaterdthum J, Tuntiwattanapibul Y, Sripalakij S, Danchaivijitr S: Bacterial flora-A potential source of endophthalmitis after cataract surgery. J Med Assoc Thai 2005, 88(Suppl 10):S49-S53.

33. Seni J, Najjuka CF, Kateete DP, Makobore P, Joloba ML, Kajumbula H, Kapesa A, Bwanga F: Antimicrobial resistance in hospitalized surgical patients: a silently emerging public health concern in Uganda. BMC Res Notes 2013, 6:298.

34. Liesegang TJ: Use of antimicrobials to prevent postoperative infection in patients with cataracts. Curr Opin Ophthalmol 2001, 12(1):68-74.

doi:10.1186/1471-2415-13-71

Cite this article as: Mshangila et al:: External ocular surface bacterial isolates and their antimicrobial susceptibility patterns among pre-operative cataract patients at Mulago National Hospital in Kampala, Uganda. BMC Ophthalmology 2013 13:71.

\section{Submit your next manuscript to BioMed Central and take full advantage of:}

- Convenient online submission

- Thorough peer review

- No space constraints or color figure charges

- Immediate publication on acceptance

- Inclusion in PubMed, CAS, Scopus and Google Scholar

- Research which is freely available for redistribution 